\title{
GENERATION TIME AND INTRINSIC RATES OF NATURAL INCREASE IN WILDEBEESTE (CONNOCHAETES TAURINUS ALBOJUBATUS THOMAS)
}

\author{
R. M. WATSON \\ P.O. Box 15068, Nairobi, Kenya \\ (Received 23rd December 1969)
}

In a population growing in size exponentially, the relation between numbers and time is given by the expression:

$$
\mathrm{N}_{\mathrm{T}}=\mathrm{N}_{\mathrm{O}} \mathrm{e}^{\mathrm{rT}}
$$

where $T$ is the mean length of a generation (the generation time); $N_{O}$ and $N_{T}$ are the numbers in the population at times separated by an interval of one generation; $r$ is the intrinsic rate of natural increase.

$$
\text { Thus the generation time } T=\frac{\log _{e} R_{o}}{r}
$$

where $R_{o}$ is the net reproductive rate $\left(=e^{r T}\right) ; r$ is the intrinsic rate of natural increase. As Birch (1948) points out, $T$ cannot be accurately calculated without an accurate value for $r$. However, this author offers an approximate method, assuming that all the breeding for one generation takes place at one moment of time, with successive generations consequently spaced at equal time intervals of T units, as was first proposed by Dublin \& Lotka (1925).

Using this assumption, his expression is:

$$
\mathrm{T}=\frac{\Sigma \mathrm{xl}^{\prime}{ }_{\mathrm{x}} \cdot \mathrm{m}_{\mathrm{x}}}{\Sigma \mathrm{l}_{\mathrm{x}} \cdot \mathrm{m}_{\mathrm{x}}}
$$

where $\mathrm{x}$ is the pivotal age of any age group in the female life-table; $1^{\prime}{ }_{\mathrm{x}}$ is the probable number of wildebeeste alive at pivotal age, $\mathrm{x}$, divided by 1000 (cohort of 1000); $\mathrm{m}_{\mathrm{x}}$ is the mean number of female offspring produced over the span of the age-group, namely, the age-specific fecundity. In my earlier paper (Watson, 1969), a generation time of 1 year was incorrectly deduced, this being the interval between successive reproductive periods and not the mean interval between reproduction in successive generations (i.e. the mean generation time). The data of Watson (1969) allow computation of a generation time of $6 \cdot 356$ years.

An alternative, more accurate calculation of $\mathrm{T}$ is possible from the earlier quoted expression

$$
\mathrm{T}=\frac{\log _{\mathrm{e}} \mathrm{R}_{\mathrm{o}}}{\mathrm{r}} .
$$

$R_{0}$, the net reproductive rate, is derived from the summation of $1^{\prime}{ }_{x} m_{x}$ terms in 
the female life-table (Watson, 1969). The intrinsic rate of natural increase, $r$, is calculated as suggested by Birch (1948), from substitution in the expression:

$$
\Sigma \mathrm{e}^{-\mathrm{rx}} 1^{\prime} \mathrm{m}_{\mathrm{x}}=1 \text {, }
$$

which is preferred to:

$$
\int_{0}^{\infty}-\mathrm{rx} 1^{\prime} \mathrm{m}_{\mathrm{x}}=1
$$

because of greater simplicity in calculation, and because the seasonal nature of reproduction in wildebeeste (Watson, 1969) makes the former a more accurate statement for this species. $\mathbf{R}_{\mathbf{o}}$ was previously calculated in Watson (1969) as 1.594 , and $\mathrm{r}$ from the above expression becomes 0.0796 . Thus, the generation time by this more accurate method is 5.857 years.

The different values for the Serengeti wildebeeste population's parameters are set out for ease of reference in Table 1. Comparison of the two methods for the calculation of generation time and intrinsic rate of natural increase suggests that no significant loss in accuracy results from using the approximate and much simpler method (method 2 in Table 1). In view of the approximate nature of most data collected on large wild mammals and of the broad similarities of their reproductive parameters, it is of general value to ecologists and mammologists to know that the important population parameters can be calculated from life-tables and age-specific fecundities by simple arithmetic means alone, to levels of accuracy matching that of their data.

The major correction required in Watson's (1969) work resulting from the incorrect assumption that $\mathrm{T}$ has a value of 1 year, apart from the intrinsic and finite rates of increase, concerns the percentage contribution of each age group to parameter $r$. Whereas the first two reproductive age groups were incorrectly considered to have made a contribution of $58 \%$ to the value of $r$, correct data transforms this value to $29 \%$. (The last two columns for the female life-table of Watson (1969) are set out correctly in Table 2.) This correction must lead to a corresponding re-assessment of the influence of female sexual maturation rates, as affecting the schedule of age-specific fecundities, in mechanisms of population adjustment for wildebeeste. This receives more detailed treatment in the following paragraph, which considers some ecological implications of generation time.

Watson (1969) considers in his last two paragraphs how reproductive mechanisms can influence the intrinsic rate of natural increase, and how changes in this parameter are of significance in conservation problems. Although the error in interpreting generation time, with consequent miscalculation of intrinsic rates of natural increase and finite rates of increase, has not invalidated the major arguments of these paragraphs, nevertheless it seems of value to consider some of the ecological implications of generation time in these contexts.

Ghanges in the schedule of age-specific fecundities need not influence the value for generation time, although the intrinsic rate of natural increase is unlikely to remain unchanged. Changes in female maturation rates in wildebeeste, which would be operative on values for the age-specific fecundity at pivotal ages two and three alone, will considerably change the frequency distribution of the $1^{\prime}{ }_{x} m_{x}$ terms and, hence, mediate changes in parameters $T$ and 


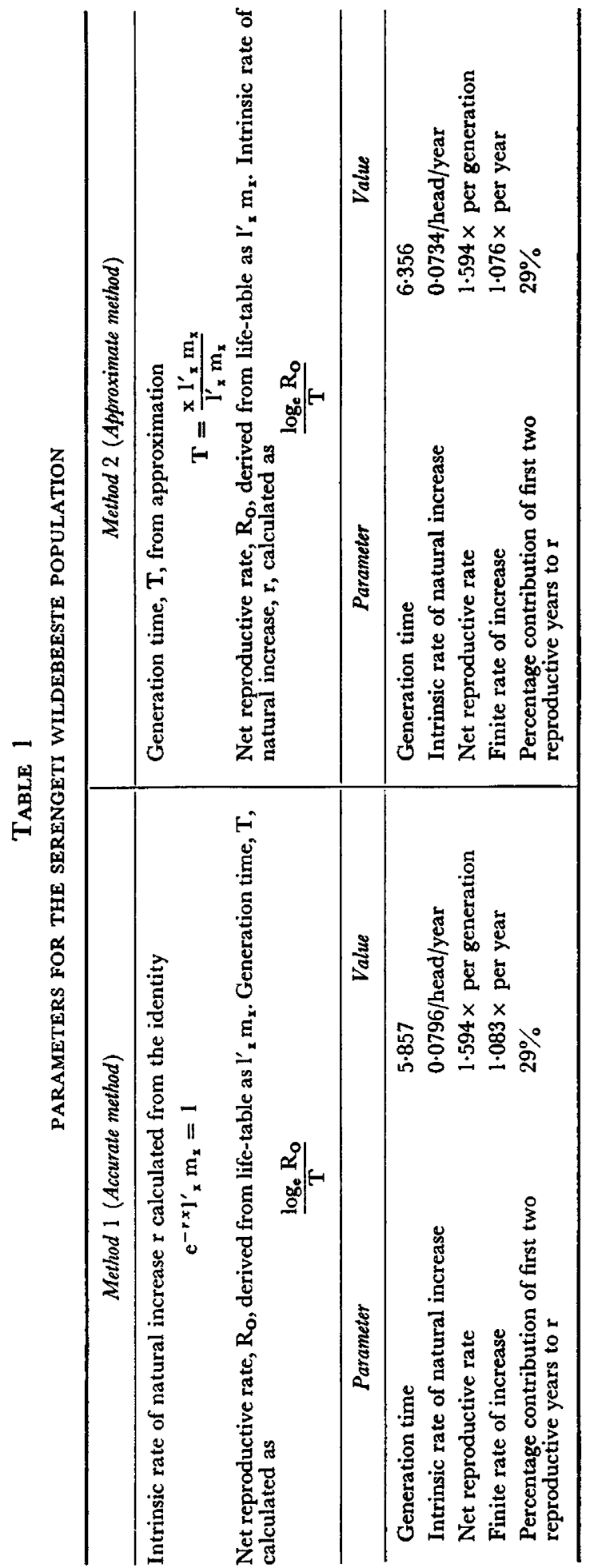


$r$ as already observed. On the other hand, a general change in wildebeeste fecundity for all age groups and in the same direction (i.e. a decline or rise) could occur without in any way influencing the value of $T$, although the intrinsic rate of natural increase would be affected. This contrast serves to highlight two alternatives in mechanisms of population adjustment. The one in which differing maturation rates are operating on the age schedule of fecundity for the first few reproductive years, thereby influencing both parameters $r$ and $T$; the other in which a change in fecundities at all ages leaves $T$ unchanged, or relatively so, yet effects changes in $r$. Wildebeeste in the Serengeti

TABLE 2

LIFE-TABLE FOR FEMALE WILDEBEESTE, 1962-65, WITH $\mathrm{r}$ CALCULATED AS 0.0796

\begin{tabular}{|c|c|c|c|c|c|c|c|c|}
\hline $\begin{array}{c}\text { Females } \\
\text { of } \\
\text { pivotal } \\
\text { age }(x) \\
\text { in years }\end{array}$ & $l_{x}$ & $d_{x}$ & $q_{x}$ & $p_{x}$ & $m_{x}$ & $l^{\prime}{ }_{x} m_{x}$ & $l_{x}^{\prime} m_{x}^{3-r x}$ & $\begin{array}{c}\% \text { contribution } \\
\text { to } r\end{array}$ \\
\hline Birth & 1000 & - & - & 4 & 0.00 & 0.000 & 0.0000 & 0.00 \\
\hline I & 746 & 254 & 0.25 & 5 & 0.00 & 0.000 & 0.0000 & 0.00 \\
\hline 2 & 660 & 340 & $0 \cdot 12$ & 5 & 0.19 & 0.125 & $2 \cdot 1416$ & $10 \cdot 65$ \\
\hline 3 & 571 & 429 & $0 \cdot 14$ & 4 & 0.42 & 0.239 & $3 \cdot 7800$ & 18.81 \\
\hline 4 & 523 & 477 & 0.08 & 4 & 0.48 & $0 \cdot 251$ & 3.6682 & 18.25 \\
\hline 5 & 450 & 550 & $0 \cdot 14$ & 3 & 0.48 & 0.216 & 2.9140 & 14.54 \\
\hline 6 & 379 & 621 & $0 \cdot 16$ & 3 & 0.48 & 0.181 & $2 \cdot 2541$ & $11 \cdot 22$ \\
\hline 7 & 306 & 694 & 0.19 & 3 & 0.48 & 0.147 & 1.6916 & 8.44 \\
\hline 8 & 217 & 783 & 0.29 & 2 & 0.48 & 0.104 & $1 \cdot 1048$ & 5.51 \\
\hline 9 & 160 & 840 & 0.26 & $\overline{2}$ & 0.48 & 0.077 & 0.7558 & 3.77 \\
\hline 10 & 87 & 913 & 0.47 & 2 & 0.48 & 0.042 & 0.3806 & 1.90 \\
\hline 11 & 79 & 921 & 0.09 & 4 & 0.48 & 0.038 & 0.3179 & $\begin{array}{l}1.59 \\
1.59\end{array}$ \\
\hline 12 & 71 & 929 & $0 \cdot 10$ & 5 & 0.48 & 0.034 & $0 \cdot 2628$ & 1.31 \\
\hline 13 & 63 & 937 & 0.11 & 5 & 0.48 & 0.030 & 0.2140 & 1.07 \\
\hline 14 & 47 & 953 & 0.26 & 5 & 0.48 & 0.023 & $0 \cdot 1516$ & 0.76 \\
\hline 15 & 39 & 961 & 0.17 & 5 & 0.48 & 0.019 & 0.1156 & 80 \\
\hline 16 & 39 & 961 & 0.00 & 4 & 0.48 & 0.019 & 0.1067 & \\
\hline 17 & 39 & 961 & 0.00 & 3 & 0.48 & 0.019 & 0.0986 & \\
\hline 18 & 31 & 969 & 0.21 & 2 & 0.48 & 0.015 & 0.0719 & Negligible \\
\hline 19 & 23 & 977 & 0.26 & 1 & 0.48 & 0.011 & 0.0487 & $\begin{array}{l}\text { values } \\
\text {. }\end{array}$ \\
\hline 20 & 8 & 992 & 0.65 & 1 & 0.48 & 0.004 & 0.0164 & \\
\hline 21 & 0 & 1000 & 1.00 & $\frac{1}{2}$ & 0.48 & 0.000 & 0.0000 & \\
\hline
\end{tabular}

$l_{x} m_{x}=1 \cdot 594$.

$l_{x}$ is the probable number of wildebeeste alive at pivotal age $x$ (cohort 1000).

$d_{x}$ is the probable number of wildebeeste dead at pivotal age $\mathbf{x}$ (cohort 1000).

$q_{x}$ is the probable death rate between pivotal ages $(x)$ and $(x-1)$.

$\mathrm{P}_{\mathrm{x}}$ is the probable period of life ahead of animals of age $\mathrm{x}$ to the nearest year.

$\mathbf{m}_{\mathbf{x}}$ is the mean number of female offspring produced over the span of one age group (age-specific fecundity).

$l^{\prime} m_{x}$ is the product of $m_{x}$ and $l_{x} / 1000$, and the sum of all terms is equivalent to the net reproductive rate $\mathbf{R}_{\mathbf{o}}=1.594$.

region, over the range of response observed from 1962 to 1966 , demonstrated exclusively the former mechanism. The crocodile (Crocodylus niloticus Laurenti) is reported by Graham (1969) to be an example of a species showing the latter mechanism, whereas Laws (1969) has shown that, in the African elephant (Loxodonta africana Blumenbach), both mechanisms complement each other. More information will be necessary before a fruitful evaluation of these two mechanisms in ecological terms can be made. 
Changes in the age structure of the population will influence both $\mathbf{r}$ and $\mathrm{T}$. As shown in Table 2 for wildebeeste, changes in the proportions of younger animals will more profoundly affect the parameters $r$ and $T$. Indeed, females older than 13 years make a negligible contribution to both $r$ and T. Watson (1969) points out that calf mortality, which is density-dependent, has an overriding influence on the age structure of the population (and hence, on the parameters $r$ and $T$ ) enabling the Serengeti wildebeeste population to respond sensitively and rapidly to environmental change.

I am grateful to $\mathrm{Mr} \mathrm{R}$. Allsop for pointing out the error in generation time in Watson (1969).

\section{REFERENCES}

Birch, L. C. (1948) The intrinsic rate of natural increase of an insect population. F. Anim. Ecol. 17, 15. Dublin, L. I. \& Lotka, A. A. J. (1925) On the true rate of natural increase as exemplified by the population of the United States. 1920. J. Am. statist. Ass. 20, 305.

Graham, A. D. (1969) The Lake Rudolf crocodile (Crocodylus niloticus Laurenti) population. M.Sc. thesis, University College, Nairobi.

Laws, R. M. (1969) Aspects of reproduction in the African elephant, Loxodonta africana. F. Reprod. Fert. Suppl. 6, 193.

Watson, R. M. (1969) Reproduction of wildebeeste, Connochaetes taurinus albojubatus Thomas, in the Serengeti region, and its significance to conservation. F. Reprod. Fert. Suppl. 6, 287. 